\title{
VISUAL BRANDING KAOS MESEM SITHIK
}

\author{
Novi Pradhana Putra \\ Program Pascasarjana \\ Institut Seni Indonesia Surakarta \\ JI. Ki Hadjar Dewantara No. 19 Kentingan, Jebres, Surakarta, 57126 \\ Dharsono Sony Kartika \\ ISI Surakarta
}

\begin{abstract}
ABSTRAK
Penelitian ini berjudul VISUAL BRANDING KAOS MESEM SITHIK. Penelitian membahas tentang strategi visual branding pada produk cinderamata pariwisata dari Kabupaten Tulungagung, yaitu Kaos Mesem Sithik. Permasalahan penelitian terletak pada keberadaan kaos Mesem Sithik, konsep branding kaos Mesem Sithik, dan strategi komunikasi pada visal brand Kaos Mesem Sithik. Berdasarkan hasil penelitian, diperoleh kesimpulan keberadaan kaos Mesem Sithik berawal dari gagasan komunal organisasi Paguyuban Cinta Wisata Tulungagung, yang kemudian kepengurusan produksi dipindah tangankan kepada perseorangan. Wahyu Cahyo Utomo sebagai pemilik usaha kaos Mesem Sithik lebih leluasa menuangkan gagasan idiom kebudayaan daerah Kabupaten Tulungagung kedalam visual brand produk. Perpindahan kepengurusan kaos Mesem Sithik membawa perkembangan dari segi konsep branding produk yang mencakup strategi media dan strategi visual. Desain ilustrasi yang tercetak pada permukaan kaos Mesem Sithik tidak serta merta mengungkap strategi komunikasi produk. Strategi komunikasi kaos Mesem Sithik didapatkan melalui pendekatan ikonografi Erwin Panofsky yang menkaji desain ilustrasi dalam tiga lapisan makna, pra-ikonografi, ikonografi, dan ikonologi. Dari analisis yang dilakukan, strategi komunikasi pada kaos Mesem Sithik mengedepankan keindahan visual, pemanfaatan teks sebagai penjelas universal, penekanan biaya produksi, dan kepantasan norma dalam menyampaikan idiom kebudayaan daerah Kabupaten Tulungagung sebagai brand produk.
\end{abstract}

Kata Kunci: Strategi komunikasi, visual brand, kebudayaan daerah

\begin{abstract}
This studyis entitled VISUAL BRANDING KAOS MESEM SITHIK. The research discusses about visual branding strategy on tourism souvenir product from Kabupaten Tulungagung, namely T-shirt Mesem Sithik. The problem lies on the existence of T-shirt Mesem Sithik, the branding concept of T-shirt Mesem Sithik, and communication strategies at visual brand of Mesem Sithik T-shirt. Based on the research, it can be said that the existence of T-shirt Mesem Sithik started fromthe notion of communal association Paguyuban Cinta Wisata Tulungagung that later move the management of production to individual. Wahyu Cahyo Utomo as the owner of T-shirts Mesem Sithik is more flexible to explore the cultural ideas of Tulungagung into visual brand products. The displacement of management T-shirt Mesem Sithik shows the development in terms of the concept of branding products including strategy media and visual strategy. The illustration design printed on the T-shirt Mesem Sithik doesn't necessarily show the product communication strategy. The communication strategy of T-shirt Mesem Sithik is studied through the iconography approach Erwin Panofsky that studies illustration design in three steps of meaning; they are pre-iconography, iconography, and iconology. From the analysis done, communication strategy of T-shirt Mesem Sithikputs forward the visual beautyutilizing text as universal explanation, pressing production fee, and the norms suitability in expressing cultural idioms of Tulungagung as the product brand.
\end{abstract}

Keywords: communication strategy, visual brand, rural culture

\section{A. Pengantar}

Kaos Mesem Sithik merupakan produk cinderamata pariwisata dari Kabupaten Tulungagung. Sebagai sebuah produk cinderamata pariwisata, kaos Mesem Sithik menampilkan idiom-idiom kebudayaan daerah yang diharapkan nantinya mampu berkembang menjadi identitas kebudayaan daerah Kabupaten Tulungagung. Dapat dikatakan kaos Mesem Sithik adalah salah satu media branding alternative bagi Kabupaten Tulungagung. Komitmen kaos Mesem Sithik untuk menampilkan idiom kebudayaan daerah 
Kabupaten Tulungagung, menjadikan peran kebudayaan daerah begitu penting dalam konsep product branding kaos Mesem Sithik. Kebudayaan daerah Kabupaten Tulungagung pada kaos Mesem Sithik tidak hanya berperan sebagai ornamen penghias suatu desain kaos, melainkan menjadi pesan utama yang disampaikan melalui media kaos.

Berbeda dengan brand produk sejenis, brand kaos Mesem Sithik memililiki fungsi ganda. Brand suatu produk lazimnya hanya berfungsi untuk menyampaikan jati diri produk. Sedangkan fungsi brand pada kaos Mesem Sithik selain menyampaikan jati diri produk, juga berfungsi sebagai media alternative penyampai idiom-idiom kebudayaan daerah pembentuk identitas daerah Kabupaten Tulungagung. Bedasarkan penjabaran di atas, cukup representative jika penelitian ini mengulas strategi komunikasi pada visual brand kaos Mesem Sithik, dengan alasan fungsi ganda yang melekat pada brand kaos Mesem Sithik

\section{B. Keberadaan Kaos Mesem Sithik}

Gagasan awal pembuatan kaos Mesem Sithik dicetuskan oleh organisasi kemasyarakatan yang bergerak pada bidang pariwisata di Kabupaten Tulungagung (Budiono,wawancara 5 Maret 2014). Organisasi tersebut adalah Paguyuban Cinta Wisata Tulungagung. Berawal dari organisasi ini embrio produk kaos Mesem Sithik dilahirkan hingga kemudian tumbuh berkembang menjadi produk cinderamata pariwisata dari Kabupaten Tulungagung.

Paguyuban Cinta Wisata Tulungagung atau disingkat PACIWISTU telah terbentuk pada tahun 2009. pada mulanya paguyuban ini terbentuk dari sekumpulan anggota masyarakat Kabupaten Tulungagung yang memiliki kegemaran melakukan kegiatan wisata di objek-objek wisata di Kabupaten Tulungagung. Setelah sekian banyak objek wisata di Kabupaten Tulungagung yang mereka jelajahi, perhatian mereka terfokus terhadap objek-objek wisata terpencil yang kurang mendapat perhatian oleh Pemerintah Daerah Kabupaten Tulungagung.

Pada Februari 2010 seorang mahasiswa yang juga merupakan anggota PACIWISTU, melakukan Pengabdian Masyarakat di kantor Dinas Pariwisata Kabupaten Tulungagung. Dari sinilah keberadaan PACIWISTU mulai dikenal oleh Dinas Pariwisata Kabupaten Tulungagung. Proyek kerjasama pertama antara PACIWISTU dan Dinas Pariwisata Kabupaten Tulungagung adalah pembuatan buku Katalog Wisata Kabupaten Tulungagung. Sejak saat itu, terjalin hubungan yang baik antara PACIWISTU dan Dinas Pariwista Tulungagung.
Berawal dari kepercayaan Dinas Pariwisata Kabupaten Tulungagung terhadap PACIWISTU sebagai delegasi yang mewakili Kabupaten Tulungagung untuk mempromosikan pariwisata daerahnya di event tahunan tingkat propinsi yang diadakan di Surabaya. PACIWISTU kemudian memutuskan untuk membuat kaos identitas kelompok untuk lebih memperkuat kesatuan kelompok sebagai perwakilan dari Kabupaten Tulungagung. Kaos Identitas kelompok dari Paguyuban Cinta Wisata Tulungagung inilah yang menjadi embrio awal lahirnya produk kaos Mesem Sithik.

Kaos identitas kelompok yang pada awalnya hanya untuk anggota PACIWISTU, kemudian coba dipasarkan pada event tahunan tingkat propinsi di Surabaya dan juga dipasarkan melalui jejaring sosial. Ternyata produk kaos ini dapat diterima konsumen. Semangat cinta kedaerahan dan masukan dari banyak pihak, membuat kaos Mesem Sithik mengusung konsep brand representasi idiom kebudayaan daerah Kabupaten Tulungagung. Berbeda dengan produk kaos sejenis yang berkembang dengan memanfaatkan kemapanan daerahnya sebagai daerah tujuan pariwisata, keunikan kaos Mesem Sithik dipengaruhi oleh kondisi pariwisata Kabupaten Tulungagung sendiri yang belum berkembang secara optimal. Hal ini membuat kaos Mesem Sithik selain sebagai komoditas cinderamata pariwisata, juga berfungsi sebagai media untuk mengenalkan bidang pariwisata Kabupaten Tulungagung.

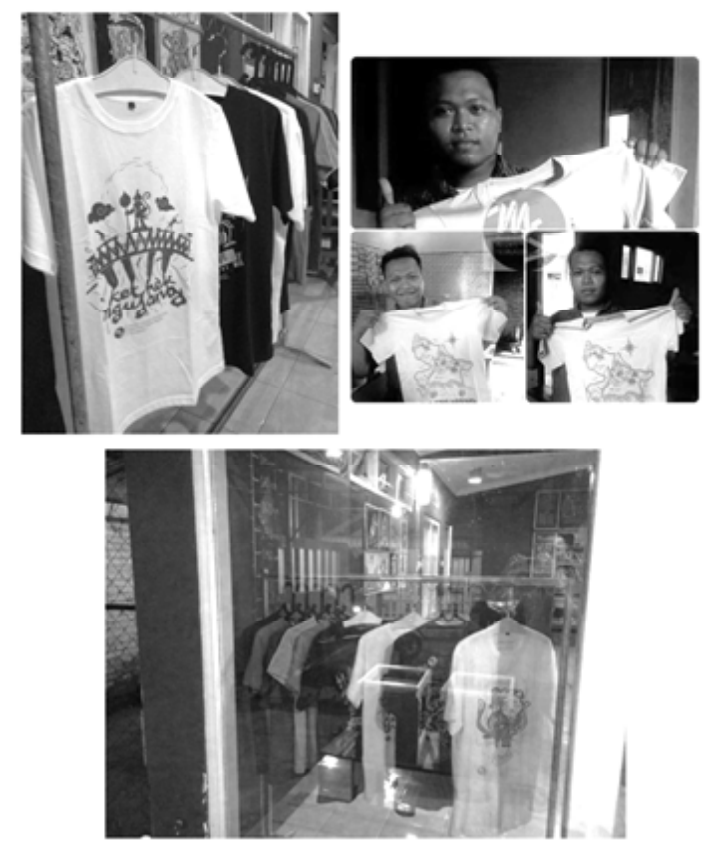

Gambar 1.Outlet penjualan Kaos Mesem Sithik. (Sumber: Foto oleh Putra, 2015) 


\section{GEARR hamisanibuson}

Berdasarkan periodisasinya terdapat dua jenis kepengurusan produksi kaos Mesem Sithik, yaitu kepengurusan produksi sebelum tahun 2011 dan kepengurusan produksi tahun 2011 sampai saat ini. Sebelum tahun 2011 kepengurusan produksi kaos dipegang oleh PACIWISTU. Sedangkan kepengurusan produksi kaos pada tahun 2011 hingga saat ini merupakan tanggungjawab penuh Wahyu Cahyo Utomo sebagai ilustrator utama kaos Mesem Sithik dan sekaligus pemodal.

Perubahan kepengurusan produksi kaos Mesem Sithik terjadi karena bertambah padatnya kegiatan PACIWISTU. PACIWISTU merupakan organisasi non profit tidak mampu lagi menangani banyaknya permintaan produk Kaos Mesem Sithik dari konsumen. Banyaknya permintaan dari konsumen menimbulkan masalah di bagian produksi dan pembagian keuntungan kepada anggota PACIWISTU. Budiono sebagai ketua PACIWISTU kemudian melimpahkan kepengurusan produksi Kaos Mesem Sithik Tulungagung kepada Wahyu Cahyo Utomo yang dinilai mampu dan memiliki modal untuk memproduksi Kaos Mesem Sithik

Sejak pertama kali diproduksi kaos Mesem Sithik hanya dijual dalam wilayah Kabupaten Kabupaten Tulungagung. Pola pemasaran seperti ini sesuai dengan kosep brand kaos Mesem Sithik sebagai produk cinderamata wisata dari Kabupaten Tulungagung. Diakui oleh wahyu selaku pemilik usaha bahwa pemasaran kaos Mesem Sithik mirip dengan pemasaran kaos Joger dari Bali. Perbedannya terletak pada outlet penjualan kaos. Jika kaos Joger dari Bali hanya dijual di outlet resmi Joger, sedangkan kaos Mesem Sithik selain dijual di outlet resmi juga dijual di toko-toko penjual cinderamata di wilayah Kabupaten Tulungagung.

Target audience merupakan sekelompok orang yang menjadi sasaran promosi suatu produk. Sebagai produk cinderamata wisata, tentu saja target audience kaos Mesem Sithik adalah wisatawan. Karena wisatawan kabupaten Tulungagung didominasi oleh wisatawan dalam negeri, maka inilah yang menjadi target audience kaos Mesem Sithik.

Media kaos merupakan media yang dapat digunakan kapan saja, di mana saja, laki-laki maupun perempuan, usia balita sampai lansia. Fleksibilitas kaos sebagai jenis pakaian membuatnya begitu populer. Produsen kaos Mesem Sithik memanfaatkan keunggulan jenis pakaian ini untuk menjaring target audience seluas-luasnya.

\section{Konsep Branding Kaos Mesem Sithik}

Konsep brand secara garis besar merupakan gagasan untuk mengkomunikasikan atau menyampaikan identitas produk (Adityawan, 2010:110). Sebagai upaya mengkomunikasikan identitas produk maka brand kaos Mesem Sithik memerlukan strategi agar komunikasi yang dilakukan efektif dan efesien dalam menyampaikan identitas produk kepada audience.

Visual branding merupakan bagian dari upaya branding produk secara keseluruhan yang memusatkan perhatian penggunaan aspek visual untuk mengkomunikasikan identitas suatu produk baik secara verbal maupun non verbal. Strategi komunikasi dalam visual branding dibedakan menjadi dua, yaitu strategi media dan strategi visual (Adityawan, 2010: 112).

Berhungan dengan objek material penelitian yaitu visual brand kaos Mesem Sithik, maka kajian mengenai strategi media dapat diartikan sebagai upaya untuk memilih sarana perantara untuk menyampaikan identitas kaos Mesem Sithik secara efektif dan efesien. Strategi media pada kaos Mesem Sithik dibedakan menjadi strategi media produk dan strategi media promosi.

Kaos Mesem Sithik merupakan produk cinderamata dari Kabupeten Tulungagung. Sebagai produk cinderamata, kaos Mesem Sithik memanfaatkan kaos sebagai media produknya. Keunggulan yang dimiliki kaos sebagai produk cinderamata antara lain terjangkau, ringan sehingga mudah dibawa (mobile), mampu mengaktualisasikan gagasan mengenai kekhasan suatu daerah (Flexibel) dan lain sebagainya (Jumanta, 2004: 12).

Jenis kaos yang digunakan pada produk kaos Mesem Sithik adalah kaos oblong lengan pendek dengan kerah o-neck. Jenis kaos ini adalah jenis kaos yang paling lazim diproduksi pelaku industri fashion. Material yang digunakan untuk bahan kaos Mesem Sithik adalah cotton combed 20 s. Kaos cinderamata wisata biasanya menggunakan jenis bahan kaos dengan harga yang lebih terjangkau daripada catton combed 20s. Kaos Mesem Sithik menggunakan material ini dengan tujuan dapat bersaing di dua pasar sekaligus, pasar kaos distro maupun kaos cinderamata wisata. Tentu saja pasar kaos cinderamata menjadi pasar utama kaos Mesem Sithik, namun dengan medium kaos yang kualitasnya diatas rata-rata. Penggunaan material kaos berkualitas unggul juga bertujuan untuk menambah daya jual, 
sekaligus bersaing dengan pesaing industri kaos cinderamata wisata lainnya.

Media sablon yang digunakan pada produk kaos Mesem Sithik berjenis sablon manual. Sablon manual adalah teknik sablon yang menggunakan peralatan seperti screen, rakel dan lainnya, sebagian besar proses penyablonan masih menggunakan keahlian manusia yang mengerjakannya. Kaos Mesem Sithik menggunakan jenis tinta sablon super white. Tinta super white dapat menyerap langsung kedalam kain saat diaplikasikan. Penggunaan sablon manual dengan tinta super white, gambar yang dihasilkan pada permukaan kaos dapat terlihat tajam dan tahan lama. Selain itu dengan teknik sablon manual, modal yang digunakan lebih terjangkau dari pada sablon digital, namun konsekuensinya waktu pengerjaan yang lebih lama.

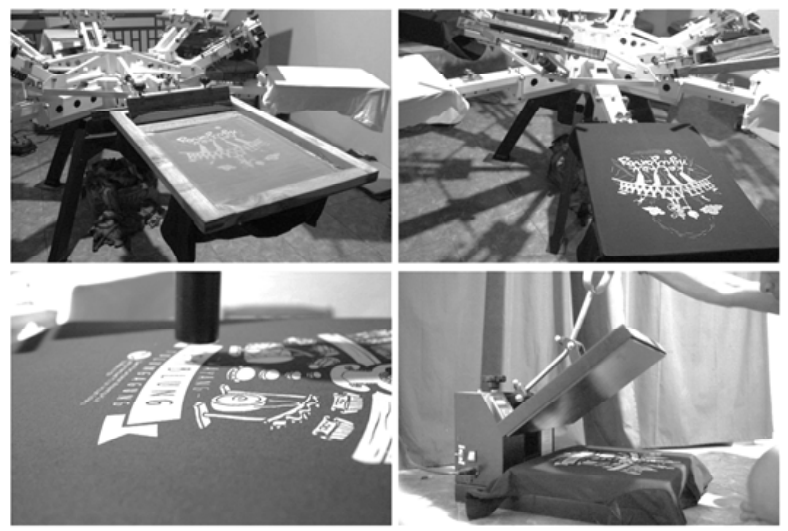

Gambar 2. Proses sablon manual kaos Mesem Sithik

(Sumber: Foto oleh Putra, 2015)

Jenis bahan kemasan kaos Mesem Sithik adalah kemasan kertas. Kemasan dari bahan kertas lebih ramah lingkungan jika dibandingkan dengan kemasan plastik. Kertas yang digunakan kaos Mesem Sithik berjenis kertas samson 80 gram. Kertas samson adalah kertas berwarna coklat dan memiliki tekstur sedikit kasar. Penggunaan kertas samson pada kemasan kemasan kaos Mesem Sithik bertujuan untuk menimbulkan kesan tradisi kedaerahan.

Tidak banyak data yang didapat mengenai strategi media promosi yang dilakukan kaos Mesem Sithik. Sejak pertama kali terbentuk hingga penelitian ini berlangsung kaos Mesem Sithik hanya tercatat beberapa kali melakukan promosi menggunakan media lini bawah dan sama sekali tidak pernah melakukan promosi menggunakan media lini atas. Bentuk promosi yang paling sering dilakukan adalah bentuk promosi paling primitif dari seluruh bentuk promosi yang ada, yaitu melalui media lisan. Keterbatasan modal sebagai usaha kecil menengah memberikan batasan ruang gerak terhadap jenis media apa saja yang dapat digunakan kaos Mesem Sithik untuk melakukan promosi.

Aspek visual merupakan segala sesuatu yang dapat dicerap oleh indra penglihatan manusia (Widyatmoko, 2009:72). Strategi visual pada kaos Mesem Sihik didefinisikan sebagai upaya mengatur bentuk-bentuk visual pada media yang telah dipilih sebelumnya, untuk menyampaikan identitas kaos Mesem Sithik secara efektif dan efesien.

Kaos Mesem Sithik sebagai salah satu pihak yang merepresentasikan kebudayaan daerah Kabupaten Tulungagung pada produknya, berupaya merumuskan identitas kebudaayaan apa saja yang menjadi cirikhas Kabupaten Tulungagung. Disinilah terdapat upaya rekayasa atas kebudayaan daerah. Kebudayaan seperti temanten kucing, reog kendang, wayang jemblung dilegitimasi menjadi idiom kebudayaan Kabupaten Tulungagung melalui produk kaos Mesem Sithik. Hal tersebut sah dilakukan demi upaya pelestarian kebudayaan daerah, meskipun tidak menutup kemungkinan bahwa akan ada wilayah lain yang melegitimasi kebudayaan yang sama. Pelegitimasian kebudayaan daerah dilakukan dengan melihat sebanyak mungkin perbedaan pada kebudayaan yang akan dicetak pada permukaan kaos dengan kebudayaan dari wilayah lain, sehingga meminimalisair resiko benturan kebudayaan dengan budaya mirip dengan wilayah lain. Langkah tersebut kemudian akan menyeleksi kebudayaan-kebudayaan mana yang pantas dijadikan identitas Kebudayaan daerah Kabupaten Tulungagung.

Gambar ilustrasi merupakan bentuk visual utama pada kaos Mesem Sithik. Jenis penggayaan ilustrasi yang digunakan pada kaos Mesem Sithik adalah kartun. Sebagai salah satu bentuk komunikasi grafis, kartun merupakan suatu gambar interpretatif yang menggunakan simbol-simbol untuk menyampaikan suatu pesan secara cepat dan ringkas, atau suatu sikap terhadap orang, situasi, atau kejadian-kejadian tertentu. Kartun biasanya hanya mengungkap esensi pesan yang harus disampaikan dan menuangkannya ke dalam gambar sederhana, tanpa detail, dengan menggunakan simbol-simbol, serta karakter yang mudah dikenal dan dimengerti secara cepat (Cloud, 2007:10-11).

Penggayaan ilustrasi kartun sangat sesuai dengan media kaos. Kaos Mesem Sithik melalui produk kaosnya ingin mengkomunikasikan kebudayaan daerah dari Kabupaten Tulungagung. 


\section{GEELR Jumal sori buatsa}

Berbeda dengan visualisasi pada media lain, visualisasi media kaos tidak akan dipandang secara jeli dalam jangka waktu lama melainkan hanya dipandang sepintas. Keunggulan penggayaan ilustrasi kartun yang dapat mengkomunikasikan suatu pesan secara cepat dan ringkas sangat cocok diaplikasikan pada media kaos. Dengan gambar sederhana audience akan lebih cepat membaca idiom kebudayaan daerah Kabupaten Tulungagung pada kaos Mesem Sithik

Tokoh wayang sering kali dimunculkan pada desain ilustrasi kaos Mesem Sithik. Meskipun tidak semua desain ilustrasi kaos Mesem Sithik membubuhkan tokoh wayang, namun keberadaan tokoh wayang cukup dominan. Pada kaos Mesem Sithik tokoh wayang biasanya digunakan sebagai objek pelaku yang memperagakan jenis kebudayaan tertentu. Tokoh wayang yang dipilih adalah tokoh wayang purwa. Tokoh wayang purwa sudah sangat familiar dengan kehidupan masyarakat Jawa pada umumnya. Tokoh wayang purwa sudah dikenal sejak persebaran agama hindu karena cerita yang dibawakan tokoh wayang purwa merupakan bagian kitab agama hindu yaitu Ramayana dan Mahabarata. Meskipun mayoritas masyarakat di Jawa sudah memeluk agama Islam namun nilai luhur yang dibawa tokoh-tokoh wayang masih terus hidup dalam khasanah kebudayaan di Jawa. Alasan tersebut yang membuat wahyu sebagai ilustrator utama sekaligus pemilik membubuhkan tokoh wayang pada desain ilustrasi kaos Mesem Sithik.

Jenis huruf yang paling sering digunakan pada visualisasi desain kaos Mesem Sithik adalah script dan cursive. Kedua jenis huruf tersebut berbentuk menyerupai handwriting atau tulisan tangan manusia. Script, hurufnya kecil-kecil dan saling menyambung, sedangkan cursive tidak (Rustan, 2010: 47). Jenis huruf kedua yang biasa digunakan dalam desain kaos Mesem Sithik adalah Miscellaneous. Miscellaneous, merupakan pengembangan dari bentuk-bentuk yang sudahada. Ditambah hiasan dan ornamen, atau garisgaris dekoratif. Kesan yang dimiliki adalah dekoratif dan ornamental. Kesan yang ingin ditampilkan dengan penggunaan jenis huruf Script, Cursive, Miscellaneous pada desain kaos Mesem Sithik adalah kesan vintage.

\section{Ikonografi pada Kaos Mesem Sithik}

Kata iconography berasal dari bahasa Yunani, terdiri atas kata aekon yang berarti sebuah gambar dan kata graphe yang berarti tulisan. Secara harafiah
Ikonografi berarti "menulis dengan gambar". Ikonografi lazim dimengerti sebagai kajian tentang tanda yang memiliki referensi, dan merupakan sebuah ladang luas yang objeknya kajiannya mencakup berbagai disiplin pemikiran. Ikonografi merupakan cabang dari sejarah seni yang memiliki pokok kajian yang berkaitan dengan sisi manusia (subject matter) dan makna dari suatu karya seni sebagai sesuatu yang bertolak belakang dengan bentuk karya tersebut (sisi formalisnya) (Panofsky, 1939:3). Istilah ini juga digunakan di beberapa bidang akademik di luar sejarah seni, seperti semiotika dan studi media massa. Teori lkon yang dijadikan sebagai landasan penelitian ini adalah teori ikon yang diajukan oleh Erwin Panofsky. Teori ini berbeda dengan teori semiotika Charles Sanders Pierce yang membagi tanda dalam tiga jenis yaitu simbol, ikon, dan index.

Erwin Panofsky menjelaskan, ikonografi merupakan kajian yang memperhatikan konfigurasi dari gambar pada suatu karya untuk mengetahui makna yang tersembunyi. Selanjutnya Panofsky memberi tahapan dalam menganalisis, yaitu tahap preiconographical, iconography, dan iconology. Erwin Panofsky dalam pemikirannya di buku Meaning in the Visual Art (1955) mengklaim bahwa ikonografi bersifat deskriptif dan classificatory, sedangkan ikonologi bersifat identifikasi. Melalui pendekatan iconography (ikonografis) dan iconology (ikonologi) maka sebuah pesan piktorial dapat diinterpretasikan makna yang terkandung di dalamnya. Sulit untuk membedakan antara ikonografi dan Ikonologi, karena kedua konsep diajukan oleh Panofsky dan merupakan bagian dari metode analisis isi seni. Namun kemudian teori pengkajian tentang ikon ini lebih populer disebut dengan teori ikonografi. Sebagai salah satu kajian tentang interpretasi makna karya seni rupa, ikonografi merupakan pendekatan yang mempertanyakan representasi dan makna yang tersembunyi dari sebuah karya visual (Van Leeuwen, 2001: 93).

Ikonografi membedakan tiga lapisan makna dari suatu gambar: arti/makna gambar (representational meaning), simbolisme ikonografi (iconographycal symbolism), dan simbolisme ikonologi (iconological symbolism) (Van Leeuwen, 2001:100). Ketiga lapisan makna tersebut didapatkan dalam tiga tahap kajian yaitu tahap preiconographical, iconographical dan iconological. Pertama tahapan preiconographical, tahapan untuk mengidentifikasi melalui hal-hal yang lazim dan sudah dikenal (alami). Tahapan ini dapat disebut pemahaman secara faktual dan ekspresional. Pemahaman ini didasarkan atas pengalaman masingmasing individu terhadap suatu objek gambar. Dengan 
mengamati dengan mengindentifikasi unsur artistik dari objek gambar (konfigurasi tertentu dari garis dan warna, atau bentuk dan material yang merepresentasikan objek keseharian tertentu), hubungan-hubungan yang terjadi pada objek dan identifikasi kualitas ekspresional tertentu dengan melakukan pengamatan pose atau gesture dari objek.

Tahapan kedua adalah tahapan iconographical. Tahapan untuk mengidentifikasi makna sekunder dengan melihat hubungan antara motif sebuah seni dengan tema, konsep atau makna yang lazim terhadap peristiwa yang diangkat oleh sebuah gambar. Motifmotif yang kemudian dikenali sebagai pembawa makna sekunder disebut sebagai image atau citra.

Tahapan yang ketiga sekaligus terakhir adalah tahapan iconological. Pada tahapan ini makna yang paling hakiki dan mendasar dari isi sebuah karya benar-benar dipahami. Pemahaman mengenai makna intrinsik yang terdapat dalam sebuah objek diperoleh dengn mengungkapkan prinsip-prinsip dasar yang kemudian dapat menunjukan perilaku sikap dasar dari sebuah bangsa, kurun waktu, strata sosial, ajakan religius atau filosofis tertentu. Memahami iconologi lebih dari sekedar mencari gejala, tetapi merupakan interpretasi yang mendalam dari pengetahuan teknis mengenai produksi seni, melalui pengetahuan iconographical yang luas menuju sebuah kesimpulan (Woodrow, 1999:3).

Desain Ilustrasi pada kaos Mesem Sithik seluruhnya bertemakan kebudayaan daerah Tulungagung, baik berupa gagasan, artefak, dan perilaku. Desain ilustrasi pada kajian ini dikatagorisasikan dalam tiga kategori menurut tema, yaitu tema kesenian, kuliner, dan landmark. Berdasarkan analisis yang telah dilakukan dapat diketahui strategi komunikasi kaos Mesem Sihik dalam mengkomunikasikan brand sekaligus idiom kebudayaan derah Kabupaten Tulungagung. Data strategi komunikasi didapatkan dari membandingkan desain pada beberapa ilustrasi, sehingga didapatkan data kecenderungan kaos Mesem Sithik dalam merepresentasikan pesan ke dalam bentuk ilutrasi.

Keindahan visual menjadi salah satu faktor yang dikedepankan dalam desain ilustrasi kaos Mesem Sithik. Ini dapat dilihat dari beberapa desain ilustrasi yang digambarkan tidak sepenuhnya mirip dengan bentuk asli kebudayaan daerah Kabupaten Tulungagung. Desain ilustrasi tersebut antara lain, desain ilustrasi Temanten Kucing, Reog Kendang, dan Jaranan Sentherewe. Pada desain ilustrasi Temanten Kucing, gambar kucing tidak divisualisasikan berada dalam kurungan sebagaimana kucing dalam ritual
Temanten Kucing. Desain ilustrasi Reog kendang dan Jaranan Sentherewe, tidak menampilkan elemen pertunjukan secara lengkap, melainkan hanya menampilkan sebagian elemen pertunjukan yang menjadi ciri khas utama pertunjukan tersebut. Wahyu sebagai ilustrator memilih dan mengkombinasikan bentuk-bentuk visual yang ditampilkan, sehingga keindahan secara visual dapat dicapai sekaligus idiom kebudayaan daerah yang disampaikan dapat dimengerti. Langkah tersebut ditempuh, meskipun harus mereduksi gagasan mengenai kebudayaan daerah yang disampaikan.

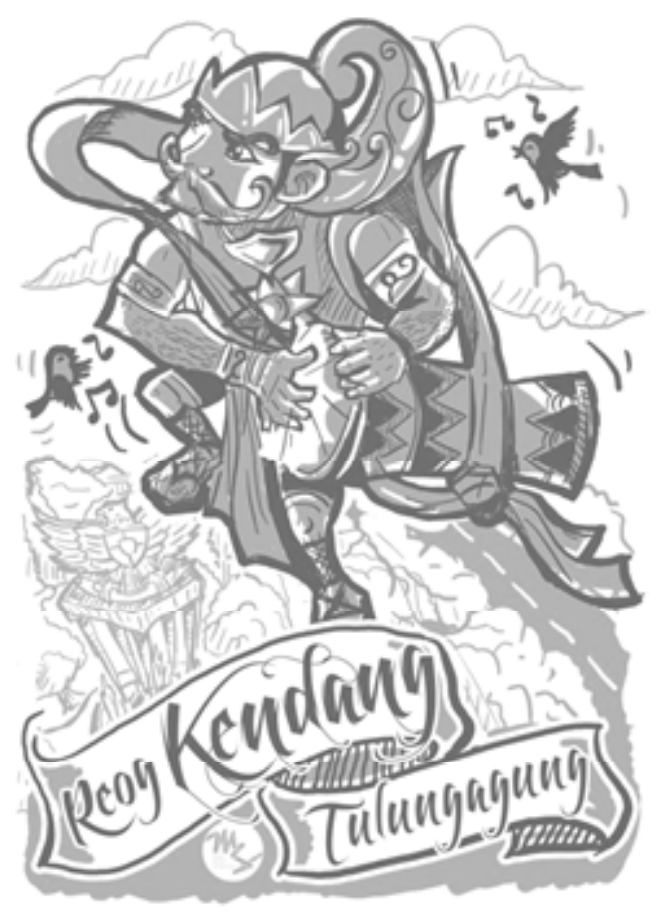

Gambar 3. Desain llustrasi Reog Kendang (Sumber: Dokumen kaos Mesem Sithik, repro digital: Putra, 2015)

Pemanfaatan teks sebagai penjelas universal begitu terlihat pada desain ilustrasi kaos Mesem Sithik. Terdapat keterangan maupun judul berupa teks pada setiap desain ilustrasi kaos Mesem Sithik. Tanpa keberadaan teks tersebut, jenis kebudayaan daerah yang digambarkan pada permukaan kaos akan sulit dimengerti audience yang berasal dari luar daerah Kabupaten Tulungagung. Peranan teks begitu penting untuk menjelaskan jenis kebudayaan yang digambarkan. Meskipun dapat dikatakan teks berperan sebagai penjelas universal pada desain ilustrasi kaos Mesem Sithik, namun cakupan teks sebagai penjelas gambar terbatas pada jenis bahasa yang digunakan. 


\section{GEELR Jumal sori buatsa}

Penekanan biaya produksi khususnya sablon, begitu terlihat pada beberapa desain ilustrasi kaos Mesem Sithik yang dibuat sederhana. Desain ilustrasi Kethek Ngujang, Jaranan Sentherewe, Gunungan Tulungagung, Wayang Jemblung, dibuat dengan menggunakan satu warna saja. Ini bertujuan untuk mempermudah proses sablon, karena hanya menggunakan satu separasi warna saja dan membutuhkan waktu lebih singkat. Proses sablon yang sederhana mampu menekan biaya modal produksi kaos dan menambah keuntungan yang di dapat produsen.

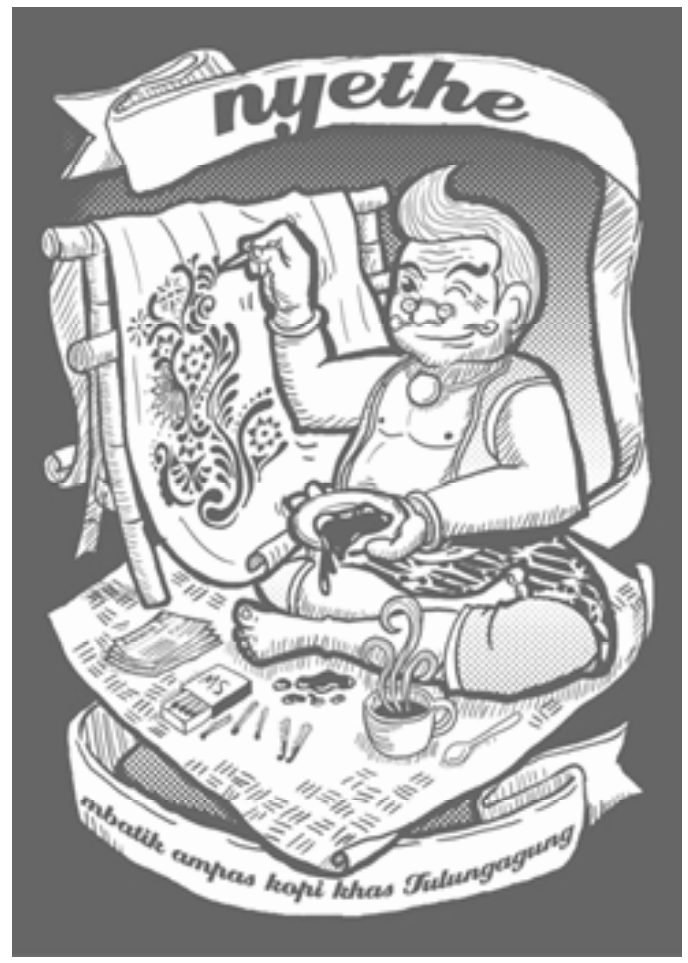

Gambar 4. Desain Ilustrasi Nyethe

(Sumber: Dokumen kaos Mesem Sithik, repro digital: Putra, 2015)

Kepantasan norma dalam memvisualisasikan kebudayaan daerah Kabupaten Tulungagung merupakan faktor penting dalam strategi komunikasi kaos Mesem Sithik. Dijumpai sisi tabu dalam beberapa kebudayaan daerah Kabupaten Tulungagung yang tidak ditampilkan pada desain ilustrasi kaos Mesem Sithik. Ini dilakukan, mengingat pemakai kaos Mesem Sithik mencakup semua golongan usia. Penghilangan sisi tabu kebudayaan, dapat dilihat pada desain ilustrasi Nyethe dan Kethek Ngujang. Desain ilustrasi Nyethe wahyu tidak menampilkan gambar rokok, padahal nyethe dimaknai oleh masyarakat Tulungagung sebagai kegiatan melukis batang rokok menggunakan ampas kopi. Sedangkan desain ilustrasi Kethek Ngujang lebih ditekankan sebagai landmark Kabupaten Tulungagung, bukan sebagai bentuk pesugihan Kethek Ngujang.

\section{E. Kesimpulan}

Kaos Mesem Sithik mengkomunikasikan idiom-idiom kebudayaan daerah Kabupaten Tulungagung dalam bentuk ilustrasi yang tercetak diatas permukaan kaos. Ilustrasi tersebut merupakan bagian dari visual brand kaos Mesem Sithik dan seharusnya dibuat dengan menerapkan konsepkonsep branding yang ada. Dari sepuluh desain yang telah dikaji terdapat beberapa desain yang tidak sepenuhnya menerapkan konsep branding produk. Beberapa desain ilustrasi juga tidak memvisualkan kebudayaan daerah Kabupaten Tulungagung secara jujur atau apa adanya, melainkan direduksi sedemikian rupa agar kebudayaan yang divisualkan dapat dinikmati semua golongan usia. Beberapa anomaly penerapan konsep branding kaos Mesem Sithik dapat ditemui pada kajian strategi komunikasi pada desain ilustrasi Nyethe, Kethek Ngujang, Temanten Kucing, dan lain sebagainya.

Keindahan visual, pemanfaatan teks sebagai penjelas universal, penekanan biaya produksi khususnya sablon, dan kepantasan norma menjadi strategi komunikasi utama kaos Mesem Sithik menyampaikan idiom-idiom kebudayaan Kabupaten Tulungagung. Konsep branding pada produk kaos Mesem Sithik berkembang sesuai permasalahan komunikasi yang dihadapi produk, khususnya secara visual.

\section{KEPUSTAKAAN}

Ahimsa-Putra, Heddy Shri. "Etnosains, Etnotek, dan Etnoart: Paradigma Fenomenologis Untuk Revitalisasi Kearifan Lokal", Kemajuan Terkini Riset Universitas Gajah Mada (2007): $156-176$

Brunel, Charlotte. The T-Shirt Book.New York: Assouline Publishing, 2002.

Cullum-Swan, Betsy dan P.K. Manning. Codes, Chronotypesand Everyday Objects. Toronto : University of Toronto, 2005.

Fresener, Scoot. how to Print T Shirts for Fun and Profit. Ridgefield: Union Ink Company, 1995. 
Jumanta.Kaos: Inspirasi Motif Modern dan Kata-Kata. Jakarta: PuspaSwara, 2004.

Masri, Andry. Strategi Visual. Yogyakarta: Penerbit Jalasutra, 2010.

Panofsky, Erwin. 1955. The Meaning Of Visual Art. Chicago : The University of Chicago Press

Supardi. Sejarah dan Kebudayaan Tulungagung. Malang: Penerbit Nego, 2009.
Widagdo. "Desain, Teori, dan Praktek", Seni Jurnal Pengetahuan dan Penciptaan Seni. BP ISI Yogyakarta III/03 (1993): 15-31.

Van Leuween, Theo and Carrey Jewitt. Handbook of Visual Analiysis. London: Sage Publications, 2001.

Woodrow, Ross. Introduction to iconography. Cardigion: Aberwstwyth Publications. 1999. 